\title{
O espaço da psiquiatria nos dispositivos de segurança na França ${ }^{1}$
}

\author{
The space of psychiatry in security devices of France
}

Claude-Olivier Doron ${ }^{2}$

\begin{abstract}
Resumo
Este artigo tem por objetivo estudar como a psiquiatria, na França, se insere num conjunto de dispositivos de segurança, os quais tomam por objeto tanto a gestão dos "riscos" relacionados aos transtornos mentais, quanto a gestão dos "riscos" de recidiva de crimes violentos. Além disso, este artigo tem como propósito estudar a posição da psiquiatria, de um lado, no cerne do que se convém de chamar de "dispositivo de saúde mental" e, de outro, no centro do dispositivo penal, sendo que ambos conheceram, nessas últimas décadas, algumas transformações análogas, que os fazem antes de tudo dispositivos de segurança no estrito sentido do termo promovido por Michel Foucault. Expõe-se aqui um quadro geral, rápido e esquemático a fim de abrir futuras discussões.
\end{abstract}

Palavras-Chave: Dispositivo de segurança. Psiquiatria. França.

\section{Abstract}

This article aims to study how the psychiatry, in France, is within a set of security devices, which focus in the management of the "risks" related to mental disorders as much as the management of "risks" of recurrent violent crimes. Besides, this article has as its focal point to study the position of psychiatry, on one hand, the center of what is to be called "mental health device" and, on the other, in the center of the legal devices, being that both have met, in the last decades, some resembling transformations that make them mainly safety devices in the strict meaning of the term promoted by Michel Foucault.

Keywords: Security device. Psychiatry. France.

1 Este artigo deve ser lido como um resumo de pesquisas anteriores. Para maiores detalhes e referências, consultar os artigos de Claude-Olivier Doron sobre a inserção da psiquiatria no dispositivo de saúde mental ou no dispositivo penal, concebidos como dispositivos de segurança: "Ce que "soin" veut dire. Quelques réflexions à propos d'une substitution de mots dans la loi du 5 juillet 2011", Journal français de psychiatrie, 2013/1, n³8, p. 19-21; "La volonté de soigner: d'un singlier désir de soin dans les politiques pénales", in Lefève, C., Worms, F. (dir.), La philosophie du soin, Paris, PUF, 2010; "Une volonté infinie de sécurité: vers une rupture générale dans les politiques pénales?" in Chevallier, P. \& Greacen, T. (dir.), Folie et justice: relire Foucault, Paris, Erès, 2009; "La maladie mentale en question" in Missa, J-N (dir.), Les maladies mentales. Cahiers du Centre Canguilhem, $\mathrm{n}^{\circ} 2$, Paris, PUF, 2008; "Une chaîne qui laisse toute liberté de faire le bien et qui ne permette que très difficilement de commettre le mal", in The Carceral Notebooks, vol. 4, dir. B. Harcourt, Jul. 2008, p. 101-130; "La rétention de sûreté: vers un nouveau type de positivisme juridique?", L'Information psychiatrique, $n^{\circ} 6,2008$, p. 533-541. Quero agradecer de todo meu coração a Mariana Broglia de Moura pela tradução deste artigo.

${ }^{2}$ Membro da Universidade Paris Diderot, Centro de História e Filosofia das Ciências. E-mail: colivierdoron@gmail.com

Esta obra foi licenciada com uma Licença Creative Commons - Atribuição 3.0 Não Adaptada 


\section{Introdução}

O que entendemos primeiramente por "dispositivos de segurança"? E em que sentido se pode dizer que isto se refere a uma matriz operacional para compreender as evoluções que afetaram o campo do governo da loucura e o campo do governo do crime desde a década de 1980? Para uma exposição mais detalhada, indicamos a aula do Michel Foucault Segurança, território, população, publicada no Brasil em 2008. Valorizaremos aqui somente alguns pontos, em relação à psiquiatria e ao seu lugar nos dispositivos de gestão do crime e da doença mental.

Foucault propõe a distinção entre três matrizes no que diz respeito ao governo dos homens, ou seja, três modalidades diferentes para interrogar as condutas dos homens e para regrá-las, e organizá-las, etc. Três modalidades que, e é preciso sublinhar imediatamente, não são necessariamente contraditórias e não se sucedem, de forma alguma, como se uma substituísse a outra. É preciso analisar em detalhe as relações complexas de subordinação, de contradição ou de reforço que elas tecem entre si.

\section{Dispositivo legal e dispositivo disciplinar}

A primeira é o dispositivo legal, que interroga fundamentalmente as condutas em termos de atos interditos por uma lei e de castigo correspondente a essa infração. Esse dispositivo contém em si uma determinada visão do sujeito como "soberano" - ou seja, capaz de atribuir a ele mesmo, a sua própria lei ou de se governar segundo a lei -; como suscetível de adentrar as relações contratuais definidas pelo Direito; como munido de determinados direitos, mais precisamente, que limitam as soberanias que podem ser exercidas sobre ele, que limitam, por exemplo, os direitos que a sociedade, o soberano, etc., podem exercer sobre ele. Trata-se de um sujeito fundamentalmente jurídico-político e a técnica de governo pela qual ele prima, neste caso, é precisamente o direito e o exercício dos direitos.

Essa técnica comporta múltiplas limitações: por exemplo, é impossível nesse regime - trancafiar ou confinar uma pessoa, ou seja, privá-la dos seus direitos de ir e vir, sem que ela tenha cometido um ato que viole uma lei, salvo, precisamente, nos casos definidos pela lei. E, mesmo assim, é preciso respeitar todo Cad. de Pesq. Interdisc. em Ci-s. Hum-s., Florianópolis, ISSN 1984-8951 v.15, n.107, p. 7-28, ago/dez 2014 
um conjunto de regras, de procedimentos, etc. que visam a regulamentar o arbitrário potencial. Esses procedimentos podem ser verificados - como sendo a legitimação do confinamento - pela autoridade competente, ou seja, o judiciário. Ou ainda: nesse regime, uma pena corresponde a uma infração bem definida: não é possível penalizar alguém fora de toda infração; se então queremos penalizar - trancafiar, confinar, controlar. - alguém fora do quadro da infração, a fim de prevenir o cometimento (ou a recidiva) de uma infração, em nome, por exemplo, do seu "perigo", é preciso se situar em outro regime e arrumar um lugar, no Direito, para este.

A partir dessas considerações é fácil compreender duas coisas: 1) A psiquiatria tem por primeira característica fundar algumas práticas derrogatórias a esse regime. É verdade, historicamente, que o alienismo se construiu, em particular na França através da lei de 1838, como um dispositivo alternativo a um confinamento regrado pela lei e controlado pelo juiz. Esse internamento passava pela autoridade administrativa, alternando por vezes o pedido das famílias, ou o "rumor público" e era validado pelo certificado do alienista. Esse dispositivo derrogatório era fundado por dois princípios: A. O fato de que, no fundo, o sujeito louco não era o seu próprio soberano, incapaz de se governar, e o de que, mostrando-se enquanto tal, não poderia ser abraçado pelo sistema legal: ele era alienado. B. O fato que ele era a causa de um "perigo eminente" atestado pelo "certificado de um médico ou por uma notoriedade pública". Esse "perigo eminente" justificava uma ação anterior à infração que ele pudesse cometer: toda a complexidade se configura, então, em identificar e prever o perigo.

A estes dois princípios correspondiam dois elementos de legitimidade do alienismo: A. Ele era o saber das alienações mentais: na falta de conhecimento de suas causas e naturezas, ele sabia ao menos identificá-las. B. Ele dispunha de todo um conjunto de técnicas que permitiam curá-las ou, por falta de cura, ao menos proteger a sociedade de um "perigo eminente" e, em particular, uma instituição: o manicômio. Notemos que, no que tange ao verdadeiro, do lado da loucura propriamente dita, o alienismo reivindicou bem rápido do lado do crime. Nesse ponto de vista não insistiremos, mas os conceitos que no final do século XIX fundaram o movimento da "defesa social" e o "positivismo criminológico" são em boa parte conceitos psiquiátricos. A diferença é que, no caso da defesa social, trata-se menos Cad. de Pesq. Interdisc. em Ci-s. Hum-s., Florianópolis, ISSN 1984-8951 
de fundar um regime derrogatório ao sistema legal do que de se livrar do sistema legal, de se livrar dessas abstrações que são a infração, o crime, o sujeito de direito, e de refundar a prática penal inteira a partir de outras bases, a partir da "periculosidade" de um sujeito criminoso, concebido dentro da sua realidade antropológica e psicológica; sem esperar a infração, mas prevenindo-a em nome desse estado perigoso; sem limitar a pena a uma simples retribuição de um crime, mas pensando-a como ilimitada e indefinida, fundada na periculosidade e não na infração em si (DORON, 2008b). Nesse ponto, voltaremos mais tarde.

2) De outro lado, é fácil de compreender que uma das estratégias das críticas de uma parte da psiquiatria (e poderíamos dizer o mesmo da prisão) foi aliás, muito cedo - a de denunciar esse regime derrogatório e reivindicar: A. A reintegração do dispositivo dentro do direito comum; B.A afirmação de que o sujeitolouco não é absolutamente alienado, já que ele dispõe de capacidades e tem, então, direitos que precisam ser respeitados. O primeiro aspecto conduziu, finalmente, bem recentemente na França (que, sobre esse aspecto, estava bem atrasada), à introdução de um controle judiciário sistemático nas medidas de hospitalização sem consentimento ${ }^{3}$. O segundo aspecto conduziu, nessas últimas décadas, a uma valorização dos "direitos dos doentes" e de suas famílias e, sobretudo, ao desenvolvimento de múltiplas práticas que visam a se apoiar sobre as capacidades dos doentes (empowerment, diretivas antecipadas, etc.). Uma das ideias principais que foram defendidas, contra a visão "alienista", é que o sujeito doente não é abolido na sua doença: ele é capaz de tomar decisões, de se governar, de se cuidar. Mas essa ideia tem um inverso: isso significa também que podemos delegar-lhe tranquilamente seu próprio acompanhamento e responsabilizá-lo.

Direcionamo-nos a segunda matriz de governo dos homens descrita por Foucault, que é certamente a mais conhecida: o dispositivo disciplinar ${ }^{4}$. Uma das teses centrais de Foucault é que essa matriz tem a sua própria genealogia,

\footnotetext{
${ }^{3}$ Este controle judiciário sistemático foi introduzido pela lei de 5 de julho 2011, modificada em seguida pela lei de 27 de setembro 2013.

${ }^{4}$ Sobre essa matriz, consultar Surveiller et punir (1975), trad. port., Vigiar e punir. Nascimento da prisão, Lisboa, Ediçoes 70, 2013; La société punitive. Cours au Collège de France. 1972-1973, Paris, Hautes Etudes/EHESS-Gallimard-Seuil, 2013 ; Le pouvoir psychiatrique (1973-1974), trad. port., O poder psiquiatrico, Martins Fontes, 2006 ; Les anormaux (1975-1975), trad. port., Os anormais, Martins Fontes, 2001.
} 
independentemente do aparelho de Estado e das relações político-jurídicas e, sobretudo, que essa matriz vai vir a caracterizar todo um conjunto de instituições no século XVIII e, sobretudo, no século XIX, entre elas a prisão e o alienismo. De outra forma, o que caracteriza fundamentalmente o alienismo é o fato de este ser um tipo de saber/poder disciplinar; aliás, é a mesma coisa do que o que é chamado no século XIX de "ciência penitenciária" e, na verdade, até mesmo algumas das funções da prisão no dispositivo penal. É claro que a prisão é uma pena, um castigo que responde a uma infração definida pela lei: ela se inscreve em um dispositivo legal. Na verdade, ela é muito mais do que isso: ela é, também, uma prática disciplinar com o intuito de corrigir, de multar, de transformar um sujeito em função de um determinado número de normas; ela produz um saber preciso sobre as capacidades do sujeito, suas resistências e seus desvios em relação a essas normas; ela supõe todo um conjunto de técnicas específicas visadas a transformar o sujeito e a se ajustar às suas capacidades. Ou seja, o sujeito da prisão não é só o sujeito da lei. De fato, existem, durante todo o século XIX, inúmeros debates sobre a maneira conveniente de ajustar a pena de prisão não em função do delito, ato caracterizado pela lei, mas em função das tendências, dos graus de perversidade, da periculosidade, etc. do criminoso concebido na sua realidade antropológica.

Eis aqui um ponto sobre o qual a psiquiatria vai, desde os anos 1840, particularmente com Voisin ou Ferrus, reivindicar um papel: a psiquiatria, como a ciência penitenciária dos administradores de prisão, vai se focalizar nas tendências, nas potencialidades, nos traços da personalidade do sujeito criminoso, independentemente de toda infração. ${ }^{5}$

Quais são as características das disciplinas que valem a pena ser consideradas? A primeira já foi esboçada: o dispositivo disciplinar visa precisamente a intervir, anterior e posteriormente, à infração - na verdade, independentemente de toda infração e de toda lei, sobre o indivíduo-sujeito nas suas dimensões psicológicas, sociais, educativas biológicas, etc. em função de certo número de

\footnotetext{
${ }^{5}$ Para maiores detalhes, consultar Doron, Claude-Olivier, Races et dégénérescence. L'émergence des savoirs sur l'homme anormal, Thèse de doctorat, Université Paris Diderot, 2011, p. 1226-1286.
} 
normas defendidas por diversas instituições: educativas, familiares, médicas, penitenciárias, industriais, etc. Então, três elementos são importantes aqui:

1. A referência da disciplina não é mais a lei, mas a norma: seu problema central não é mais a divisão do licito/ilícito, mas do normal/anormal. É aqui, evidentemente, que virão se incrustar os saberes psiquiátricos e psicológicos, como detendo certa verdade sobre o que é normal/anormal em uma conduta. Trata-se, então, de confrontar o sujeito a uma multiplicidade de normas, de lhe inculcar essas normas e/ou de corrigir seus desvios. É importante insistir que existe aqui uma vontade forte de conformação à norma que pode ser apresentada tanto como uma correção quanto como um aperfeiçoamento ou mesmo uma terapia: cuidar é também uma maneira de trazer o sujeito a uma norma, seja ela social ou vital. Foucault mostra que não se trata de dizer simplesmente que, em questões de disciplina, a referência central é a norma. É preciso adicionar que, na disciplina, a norma é primeira, o que quer dizer que ela é posta a priori: existe uma divisão entre o normal e o anormal, por exemplo, nos comportamentos sexuais entre a função genésica normal (a reprodução) e seus desvios anormais. Os comportamentos são avaliados em detrimento dessa norma primeira e trata-se de trazê-los a essa norma e de corrigi-los. Nós veremos por que é preciso insistir nisso. Isto se diferencia bem de outra representação da "normalidade" que nós vamos encontrar nos dispositivos de segurança.

2. Se o dispositivo legal é pontual e comporta essencialmente atos relacionados às leis, aqui, o dispositivo é muito mais contínuo: ele se refere às condutas ou até mesmo à interioridade do sujeito na sua integralidade, enquanto indivíduo. É um princípio, então, de continuidade, que é também o de pôr em continuidade desvios dos mais diversos em relação às diferentes normas e à referência destas a uma unidade: a personalidade do sujeito. Essa continuidade faz com que as técnicas disciplinares colem muito mais ao indivíduo, com uma fantasia, bem conhecida, de exaustividade e de controle total. Podemos pegar como exemplo, na França, o Centro Nacional de Observação de Fresnes, onde toda conduta de uma pessoa é escrutada e avaliada (suas leituras, sua escrita, seus discursos, seus gestos, atos, o que ela come, etc.). É um princípio de continuidade, de exaustividade, que se focaliza na transformação mais ou menos radical do 
sujeito: trata-se - isso é bem sensível na Filosofia da prisão do século XIX - de transformar radicalmente o sujeito, de extirpar seus maus costumes.

3. É claro que, para operar dessa maneira, a disciplina supõe o funcionamento nos espaços fixos e relativamente fechados sobre eles mesmos: prisão, hospitais, manicômios, escolas, usinas, casernas, etc. Espaços saturados de regulamentações e de normas diversas, com as quais os sujeitos vão ser confrontados; espaços nitidamente individualizantes, isto é, focalizados no indivíduo como unidade sobre a qual é preciso trabalhar; espaços hierarquizados com vários atores que convergem sobre os indivíduos segundo um sistema piramidal cujo topo é composto por profissionais particularmente valorizados, como o alienista no seu manicômio. É importante deter-se aqui em dois pontos que devem ficar claros: A. Evidentemente, num tal sistema de governo, o que prevalece é a relação paternalista entre um indivíduo considerado relativamente passivo (resistente) e ilegítimo e um indivíduo dotado de um saber pouco contestado e legítimo. B. Se existe uma pluralidade de instituições e logo uma pluralidade de normas, estas funcionam como alguns isolados relativamente fechados, dotados de suas próprias regras, de sua ordem própria. O médico, o alienista, é então realmente autônomo: de certa forma, ele é rei em seu reino, e isso, particularmente, em nome de um determinado saber e de uma determinada relação privilegiada com a doença. Esse isolado é reforçado, aliás, pela separação muito nítida entre diferentes profissões, que têm cada uma seu próprio modo de organização e de regulação.

Não insistiremos na evidência segundo a qual a psiquiatria é um saber/poder primeiramente disciplinar, como o sistema penitenciário. Tentaremos, ao contrário de compreender um pouco sobre o que advém de tal saber/poder, disciplinar, assim que ele é integrado num dispositivo de segurança. Entretanto, iremos fazer uma série de precisões sobre o que isso implica do ponto de vista das críticas da psiquiatria. É evidente, de fato, que todos os elementos que viemos a descrever -os elementos disciplinares - da psiquiatria foram motivos de críticas virulentas na segunda metade do século $X X$, e mesmo antes. Ditas críticas, foram feitas, principalmente, por um determinado número de correntes chamadas de "antipsiquiátricas", mas que recobrem uma realidade muito diferente.

Primeiro núcleo de críticas: no que concerne ao problema da norma, encontram-se diversos trabalhos, dentre os quais os mais conhecidos são os de Cad. de Pesq. Interdisc. em Ci-s. Hum-s., Florianópolis, ISSN 1984-8951 
Foucault ou os de Thomas Szasz, que vão criticar a psiquiatria por ser uma instituição de reforço das normas sociais e que opera as "traduções" que declinam dessas normas como "doenças". Esse tipo de crítica terá um sucesso muito importante, em particular, no que concerne ao caso da homossexualidade: a definição "funcionalista" da normalidade sexual que fundava a patologização da sexualidade, definindo a priori a norma sexual e julgando os comportamentos em detrimento dessa norma, vai ser recusada. Uma das questões que é aberta, a partir dessa crítica, é a seguinte: como redefinir o "transtorno mental" independentemente da referência manifesta a uma norma colocada a priori? Em diversos casos, se chama a atenção para o critério "subjetivo" do sofrimento, o que implica o aparecimento de novos problemas. ${ }^{6}$

Segundo núcleo de críticas: é o mais celebrizado que visa ao alienismo como instituição fechada, como manicômio institucional. O manicômio é acusado de reproduzir a exclusão ligada à doença mental. É uma crítica que encontramos no Franco Basaglia, por exemplo: ela vai fundar a adoção da lei 180 na Itália, com o intuito de desinstitucionalizar à psiquiatria. Esse movimento de reformas tem também abraçado o Brasil nos anos 1980-1990. Aqui também encontramos ambiguidades. Existem essencialmente duas:

1. A desinstitucionalização é constantemente compreendida como o abandono de um modelo de manicômio - ou hospital- centralizado, em nome de uma difusão geral da psiquiatria na cidade: o que ela perde em intensidade (saindo, muito relativamente, de um modelo de confinamento), a psiquiatria ganha em extensividade. $\mathrm{Na}$ verdade, esse movimento prolonga as diversas iniciativas para sair do manicômio que existem na psiquiatria desde a primeira metade do século XIX, sendo a ideia central a de ramificar dentro o corpo social inteiro. A partir disso, a psiquiatria, vai ser cada vez mais levada a gerenciar os fluxos populacionais, a organizar algumas etapas de cuidados entre um regime aberto e fechado, a se comprometer em práticas de prevenção ou de ligação com outras instituições. Ela vai se tornar uma peça fundamental dentro de um dispositivo de saúde mental mais geral.

\footnotetext{
${ }^{6}$ Sobre esses problemas, consultar Doron, Claude-Olivier, "Soigner par la souffrance : la prise en charge des auteurs de violences sexuelles ", in Doron, C-O, Lefève, C, Masquelet, A. (dir.), Soin et subjectivité, Les Cahiers du Centre Canguilhem, n²4, Paris, PUF, 2011, p. 87-114.

Cad. de Pesq. Interdisc. em Ci-s. Hum-s., Florianópolis, ISSN 1984-8951 v. 15 , n.107, p. 7-28, ago/dez 2014
} 
2. As ambiguidades são tão fortes que o movimento de desinstitucionalização vai encontrar rapidamente as aspirações de outro movimento, o da racionalização das políticas públicas da saúde e da redução das despesas. A desinstitucionalização compreendida como reduções das hospitalizações de longa data e como algo capaz de reduzir o peso que representa os manicômios é vista como um formidável utensílio de redução das despesas. O debate em torno dessas ambiguidades, muito animado na França, é também encontrado no Brasil ${ }^{7}$.

Terceiro núcleo de críticas: se concentra nas relações de poder disciplinares, entre pacientes e médicos (relação paternalista) ou entre os diferentes intervencionistas que acompanham os pacientes (enfermeiros, psiquiatras, etc.): essa crítica dos "papéis" atribuídos a cada um encontra-se em Cooper e em Basaglia. Ela vai ter duas consequências. De um lado, se apoiando sobre as reivindicações legais concernindo os direitos dos pacientes, procura reivindicar sua autonomia e exigir uma relação mais simétrica entre pacientes e médicos. Isso levanta outros novos problemas: com os psiquiatras achando uma pena a negação da particularidade da doença mental como alienação, ou criticando o fato de que os doentes estejam sobrecarregados de responsabilidades. De outro lado, se põe em questão as fronteiras e os "papéis" profissionais entre disciplinas: a psiquiatria é integrada por uma vasta rede de profissionais que trabalham na saúde mental: educadores, assistentes sociais, enfermeiros, psicólogos, etc. e deve cooperar com eles, dividir com eles as mesmas informações.

\section{Dispositivo de segurança e saber psiquiátrico}

Tudo isso nos conduz ao que vai nos interessar agora, isto é, a maneira como a psiquiatria se integra daqui em diante num dispositivo de segurança ou então em determinados dispositivos de segurança. E não porque os papéis e funções da psiquiatria no ponto de vista legal e disciplinar desaparecem, bem ao contrário. Mas é uma questão de valorização, dominância, e podemos dizer, sem erro, que hoje, o

\footnotetext{
${ }^{7}$ Um artigo publicado em 2007 na Revista Brasileira de Psiquiatria explica como o movimento de transformação do modelo dos cuidados psiquiátricos no Brasil, passando do hospital aos serviços comunitários, provocou durante dez anos uma redução das despesas relacionadas à saúde mental de $26,7 \%$ (ANDREOLI, 2007).
} 
dominante está mais do lado da maneira como a psiquiatria se integra num conjunto de problemas de governo que definem um dispositivo de segurança. Quais são esses problemas?

Simplificando, podemos dizer que se trata antes de tudo de maximizar a relação entre liberdade e segurança, por razões que são tanto econômicas quanto políticas. Vejamos isso com mais detalhe.

1. Primeiro, se o espaço disciplinar é um espaço isolado, fechado, onde cada elemento é repartido num lugar definido, o dispositivo de segurança faz referência a um território aberto, que é ajeitado para facilitar a livre circulação e o livre movimento dos sujeitos, tudo isso antecipando e reduzindo ao máximo os riscos implicados por essa circulação. De outro lado, trata-se de permitir ao máximo a liberdade dos sujeitos - e isso, reduzindo sempre que possível os riscos aferentes a essa liberdade. Trata-se de gerar fluxos, de manter ao máximo os sujeitos num espaço aberto, mas sempre intervindo, se necessário, até que a dita liberdade se demonstre muito ameaçadora. O dispositivo de segurança é um dispositivo aberto/fechado, cujo problema central é a circulação dos elementos e a avaliação dos riscos que eles colocam.

O dispositivo da saúde mental, tal como foi organizado na França nos anos 1980-1990, é caracterizado exatamente como um espaço de segurança (DORON, 2008a). Contrariamente à situação que predominava no sistema do manicômio ou no do hospital centralizado, trata-se, aqui, de um lado, de manter ao máximo os sujeitos na comunidade e de fundar um dispositivo escalonado que visa a gerenciar de maneira flexível os sujeitos situados na comunidade: equipes de psiquiatria intervindo em domicílio ou na rua, apartamentos terapêuticos, centros de crise, centros de atenção psicossociais, leitos de observação nos prontos-socorros, etc. que permitem de se adaptar à evolução do sujeito.

A lei adotada pela França em 2011 para reorganizar a saúde mental segue exatamente a mesma direção: ela cria o que é chamado de "percursos de cuidados"o termo "percurso" é essencial em um dispositivo de segurança por designar bem essa circulação, esse fluxo. Esses percursos de cuidados vão ao encontro da passagem da noção de internação involuntária à noção de cuidados sem consentimento: o cuidado sem consentimento descentra a obrigação. Ela não é mais simplesmente localizada no hospital, num lugar fechado, mas se aplica até fora Cad. de Pesq. Interdisc. em Ci-s. Hum-s., Florianópolis, ISSN 1984-8951 v.15, n.107, p. 7-28, ago/dez 2014 
deste, na comunidade. O hospital é apresentado como solução em último recurso e para momentos de crises particularmente fortes. De outro lado, não precisamos dizer que essa evolução foi também possível com o desenvolvimento dos medicamentos (antipsicóticos em particular) que permitem ao sujeito gerenciar ao máximo seu estado e funcionar relativamente bem. Enfim: tal evolução vai ao encontro do crescimento massivo de um papel que, além de tudo, o alienista tinha somente poucas ocasiões de realizar: a avaliação sistemática do "perigo" ligado a um determinado estado. O confinamento psiquiátrico no manicômio foi fundado a partir da noção "perigo"; mas, uma vez confinada, era raro que a pessoa saísse, e, se isto acontecia, não sucedia do mesmo modo que as formas regulares e frequentes de hoje. A aceleração dos fluxos, o aumento das entradas e saídas implicam a multiplicação das operações de gestão dos riscos ligados às ditas saídas, tópico sobre o qual voltaremos em seguida. Desse modo, a psiquiatria se torna, mais do que nunca, uma insistente avaliação do perigo e da gestão dos riscos, como se eles fossem ligados à circulação dos doentes.

O que discutimos sobre o dispositivo de saúde mental funciona, também, a propósito do dispositivo penal (DORON, 2009c). De um lado, a justificativa se dá por a evolução mais característica nesses últimos anos, no que se refere à prisão: 1 . Um aumento considerável da população encarcerada, mas, sobretudo, dos fluxos de entrada e saída, para pequenas penas. 2. A integração da prisão num dispositivo geral, aberto/fechado, com o crescimento das penas alternativas à detenção e o crescimento das chamadas "medidas de segurança" que se exercem, depois do final da pena, em regime aberto. Além disso, uma das grandes evoluções do sistema penal é que a prisão tende a se tornar, cada vez mais, o elo de uma corrente mais complexa, onde muitas coisas se passam em regime aberto. Nesse quadro, sonhase com o desenvolvimento de medidas de deslocamento sob vigilância eletrônica móvel, dentre outras medidas (DORON, 2008c). 3. A prisão é cada vez mais concebida como um espaço de circulação onde o detento deve engajar um "percurso de pena", que é avaliado em diferentes momentos. Logo, o primeiro ponto a se lembrar é o de que o dispositivo penal não é mais centralizado na prisão, mas se torna um espaço aberto/fechado atravessado por fluxos e trajetórias.

De outro lado, suas missões se centralizam explicitamente na gestão dos riscos de recidiva. Na França, a lei penitenciária de 2009, que redefine as missões Cad. de Pesq. Interdisc. em Ci-s. Hum-s., Florianópolis, ISSN 1984-8951 
do dispositivo penal, introduziu explicitamente, pela primeira vez, a "luta contra a recidiva" e a prevenção do risco de recidiva como uma das três missões essenciais do dispositivo. Precisamos ser claros: é obvio que isso não anula em nada o fato de que o sistema penal tenha uma função de retribuição de um crime e de correção/reinserção de um detido. Todavia, nada impede que o problema seja colocado, daqui em diante, como um problema em torno do qual gira um conjunto de instituições desde o momento do processo até depois da saída do condenado da prisão - é a questão da avaliação e da gestão do risco de recidiva.

Esses dispositivos de segurança, justamente por serem fundamentalmente abertos e circulares, supõem a fluidificação das relações entre as diferentes instituições, o fato que elas entrem em uma rede e a supressão - ou a renegociação - das fronteiras existentes entre os diferentes isolados disciplinares. Existe, assim, um movimento bem forte de não confinamento e de contato na saúde mental, no qual colaboram profissionais da psiquiatria, do serviço social, da municipalidade, autoridades judiciárias, policiais e, às vezes, até mesmo associações de usuários.

2. O segundo elemento essencial em um dispositivo de segurança é o seguinte: se o dispositivo disciplinar toma o indivíduo como sujeito fundamental e se concentra antes de tudo a nível individual, o problema fundamental do dispositivo de segurança se dá na relação entre dois níveis: o nível da singularidade e o nível da população. O dispositivo de segurança se focaliza ao nível da população. O que isso quer dizer? Primeiro, que, em um dispositivo de segurança, parte-se do conjunto de eventos tais como eles são dados. Não se opera, a priori, uma divisão entre o que é uma norma transcendental, ideal, e alguns fenômenos que se tornam essas normas. Parte-se, então, do conjunto de fenômenos, em que se reparam regularidades estatísticas, as quais vão caracterizar a normalidade de tais fenômenos. Estudamse, para isso, as distribuições relativas a determinados fenômenos em uma dada população (por exemplo, episódios depressivos ou suicídios) e se tenta, a partir disso, identificar algumas correlações estatísticas entre certas variáveis. Esses aumentos, esses desvios em relação a um índice julgado optimizado, são considerados anormais.

Tudo isso tem um conjunto de consequências muito importantes:

A. Primeiramente, não se opera uma divisão descontínua entre um fenômeno absolutamente anormal e um fenômeno normal: tudo é uma questão de frequência, Cad. de Pesq. Interdisc. em Ci-s. Hum-s., Florianópolis, ISSN 1984-8951 
e a questão central vai consistir em fixar um limiar que, se ultrapassado, permite estimar que o fenômeno é significativo, ou seja, este se torna problemático. Esse é um dos princípios que caracterizam a noção de transtorno mental no DSM: é uma questão de frequência; é preciso, por exemplo, que um fenômeno se repita "ao menos cinco vezes em seis meses" para virar o sintoma de um transtorno. Não precisamos falar que isso implica uma questão central: como o limiar é fixado? Quem o fixa? Existe, a partir daí, um continuum muito nítido que se estabelece entre o normal e o patológico. O que acabamos de definir sobre o "transtorno" individual vale a fortiori a nível das populações: a questão central é a da determinação do limiar a partir do qual um fenômeno se torna um problema que justifica a intervenção pública: será que $3 \%$ de suicídios em uma população deve ser considerado como um nível de suicídios normal, ou isso justifica uma intervenção? Será que $3 \%$ de recidivas de estupros justifica certas medidas?

Esse é o ponto essencial. Em um dispositivo de segurança, dever-se-ia, logicamente, aceitar, em certa medida, a normalidade de certo nível de ocorrências dos fenômenos (crimes, suicídios, doenças, etc.) no nível da população. Devemos operar uma divisão necessária entre um nível de singularidade, que pode ficar na incerteza, e um nível pertinente para a ação pública, que é o da série dos fenômenos assim que eles atingem uma determinada frequência estatística. A grande questão é essa: a partir de quais critérios e sobre que ponto se fixa o limiar a partir do qual se considera que é fundamental o fato de agir? Voltaremos em seguida sobre esse ponto: Essa é toda a questão colocada pelo conceito de "risco" e a avaliação riscos/benefícios, em um quadro acerca do qual é preciso maximizar a relação liberdade/segurança. ${ }^{8}$

B. Outra consequência importante: se o problema fundamental de um dispositivo de segurança é a relação singularidade/população, enfatizando o lado da população, não é preciso dizer que isso pressupõe um conjunto de procedimentos que visam a construir essa população a partir de singularidades. Alguns

\footnotetext{
${ }^{8}$ Para mais detalhes, consultar Claude-Olivier Doron, « Le principe de précaution : de l'environnement à la santé ", in Lecourt, D. (dir), La santé face au principe de précaution. Les Cahiers du Centre Canguilhem, $\mathrm{n}^{\circ} 3$, Paris, PUF, 2009, p. 3-40 e "L'au-delà du risque : précaution et attention » in Psychiatries. Revue de recherche et d'échanges, n¹55, sept. 2011, pp. 103-118.
} 
procedimentos permitem a redução da singularidade ao homogêneo, a integrá-la em uma série de casos homogêneos. É neste nível, sem dúvida, que se situa a importância acordada às classificações, do tipo DSM ou CIM, para homogeneizar as situações singulares e permitir a elaboração de dados epidemiológicos. É também nesse nível que se situam as resistências, fortes na França, dos psiquiatras de orientação psicanalítica diante do saber estatístico e epidemiológico ou perante da Evidence Based Medicine, bem como sua vontade de valorizar, ao contrário, o velho saber médico fundado nas descrições dos casos individuais.

Em um dispositivo de segurança, o saber fundamental é a epidemiologia e a estatística; a avaliação da eficácia de uma prática não se faz através do estudo de um caso singular exemplar, mas através de uma análise de coorte sobre algumas populações. Enfim - e isso é muito importante - precisamos entender que essa vontade de reduzir a singularidade ao homogêneo é, sobretudo, essencial em outro nível: o das práticas administrativas. Veremos que um dos problemas importantes que se apresentam em um dispositivo de segurança é a maximização da relação custo/eficácia, a inscrição das intervenções num cálculo econômico. Nesse quadro, no contexto do que é chamado de New Public Management, que visa a impor aos diferentes serviços do Estado algumas regras de controle da eficácia e do desempenho idênticas às das empresas privadas, uma das complexidades fundamentais é o problema da homogeneização dos atos praticados nos serviços de saúde para permitir a avaliação delas. Isso pressupõe critérios precisos para homogeneizar os diagnósticos e os atos praticados e permitir a comparação deles. É aqui que as classificações internacionais são constantemente utilizadas. Boa parte das resistências e dos combates da profissão psiquiátrica na França nesses últimos anos gira em torno desses pontos (DORON, 2009a).

Última consequência: o que significa o indivíduo em um dispositivo de segurança? Algo bem diferente do que ele é em um sistema disciplinar. Aqui, o indivíduo é pensado a partir da população, no sentido estrito do termo, representando a combinação de diferentes variáveis que primeiro foram caracterizadas ao nível das populações. Esse é um ponto que François Ewald e Robert Castel trabalharam muito bem. O "modo de individualização dos indivíduos [não se faz] mais a partir deles mesmos, do que pudesse ser a natureza deles ou o que devesse ser o ideal deles, mas a partir do grupo ao qual eles pertencem" Cad. de Pesq. Interdisc. em Ci-s. Hum-s., Florianópolis, ISSN 1984-8951 
(EWALD, 1991). Na verdade, deveríamos dizer "dos grupos", acrescentando o plural, aos quais eles pertencem e que definem tantas variáveis das quais 0 indivíduo se configura, de alguma maneira, como combinação. Define-se, por exemplo, o índice médio de recidiva de uma pessoa a partir da relação de diferentes variáveis: sua idade, a presença (ou não) de uma doença psiquiátrica, a execução (ou não) de um crime, etc., pois os testes de grupos constituídos por essas variáveis permitem determinar qual é o índice médio de recidiva.

A combinação desses índices médios, medidos em função desses grupos, ponderados de seus coeficientes de correlação à recidiva, oferece um perfil do indivíduo e dos seus fatores de riscos, neste caso, a recidiva. Uma noção essencial é essa do "perfil": o indivíduo, sob esse modo de raciocínio, é uma combinatória de variáveis determinadas a partir de grupos estatísticos (classe de idade, modos de consumo, raça ou origem, etc.) que definem um determinado perfil. A partir daí, configura-se, na América do Norte e cada vez mais na Europa, um movimento que se desenha assim: uma das funções essenciais da psiquiatria em um dispositivo de segurança é a avaliação da "periculosidade" de um doente ou de um criminoso. Para avaliá-lo, a psiquiatria se baseou durante bastante tempo no seu "saber clínico". Entretanto, um conjunto de estudos estatísticos mostrou a nulidade desse saber clínico em matéria de predição. Foi proposta, então - muito cedo nos Estados Unidos, desde os anos 1970 -, a substituição por algumas análises "atuariais" fundadas nos princípios que acabamos de descrever, consideradas muito mais nas predições (HARCOURT, 2007). Isso se deu tanto para avaliar o risco que apresenta um doente antes que o deixem sair, quanto para determinar o "risco de recidiva" de um criminoso, a fim de ajustar a resposta penal para esse risco.

3. Não se trata, então, em todo caso, de dizer que, num dispositivo de segurança, o indivíduo não exerce um papel central, mas sim que o seu modo de individuação é diferente. $O$ fato de que o indivíduo exerce um papel central pode ser demonstrado em outro nível. Tal dispositivo - e Foucault insiste nesse ponto funciona somente na liberdade: é preciso de liberdade e, sobretudo, da autonomia dos indivíduos para funcionar, das capacidades dos mesmos de regular e de dirigir parcialmente suas condutas, ao menos dentro de uma determinada margem. Foucault pressupõe uma atitude muito mais ativa dos sujeitos em relação a eles mesmos: ali onde a disciplina era marcada por relações paternalistas e assimétricas, Cad. de Pesq. Interdisc. em Ci-s. Hum-s., Florianópolis, ISSN 1984-8951 
o dispositivo de segurança pressupõe uma determinada margem de autonomia do indivíduo, uma determinada delegação ao indivíduo, mesmo doente, mesmo frágil, no gerenciamento e no controle da sua conduta e na gestão dos seus "riscos".

Nós encontramos aqui uma ambiguidade já mencionada precedentemente: o movimento que, a partir da denúncia das relações de poder disciplinares e da reivindicação dos direitos dos pacientes, promoveu a autonomia dos pacientes e a revalorização de seu espaço dentro do dispositivo de cuidados se juntou com outro movimento, vindo dos reformadores do sistema de saúde e da lógica neoliberal. A vontade neoliberal de se livrar desses pesos hospitalares em nome de um sistema mais fluido, menos custoso e descentralizado, dentro dos quais muitas coisas são delegadas ao paciente e à sua família, encontrou de maneira forte as aspirações existentes na sociedade civil, do lado particularmente das associações de doentes e de usuários, exigindo mais autonomia e mais espaço nas decisões médicas; mais liberdade e menos dissimetria. Teríamos muito a dizer sobre isso: é o que explica todo um conjunto de alianças, a priori nada evidentes, entre instituições que, na França, promovem as reformas hospitalares e o controle das práticas por motivos de racionalização e de eficácia econômica (como a Haute Autorité de Santé), determinados segmentos da profissão psiquiátrica que querem seguir no sentido da maior autonomia dos doentes, e as associações de usuários da psiquiatria.

4. O quarto elemento dos dispositivos de segurança que é preciso analisar, sendo este o mais essencial, refere-se à inscrição de todas as intervenções num cálculo de riscos/benefícios, que faz sempre a pergunta dos custos comparativos da intervenção - ou da não intervenção - e se esforça para maximizar a relação custo/benefício. O problema central do dispositivo de segurança, aqui já mencionado, é a potencialização da relação liberdade/segurança; ele implica, então, uma avaliação perpétua dos riscos aferentes à liberdade, à circulação, etc. Pareceme que, desse ponto de vista, a psiquiatria é presa a uma tensão entre duas exigências contraditórias. Segundo a lógica essencial de um dispositivo de segurança, uma divisão deveria ser operada entre um nível que podemos deixar livremente na incerteza, sem intervir, e um nível no qual se convém intervir e que é preciso regular. Quando a disciplina é exaustiva e transformadora, o dispositivo de segurança diz: "eu aceito um determinado número de distúrbios, de desvios, desde que eles não ultrapassem um determinado limiar; eu só intervenho na medida do Cad. de Pesq. Interdisc. em Ci-s. Hum-s., Florianópolis, ISSN 1984-8951 v.15, n.107, p. 7-28, ago/dez 2014 
necessário, onde esse limiar é ultrapassado". Vale também ao nível individual: no fundo, trata-se mais de regular o indivíduo, de fazer com que ele funcione bem - e os medicamentos são usados para isso - do que de tentar transformá-lo radicalmente.

Mas isso nos serve, sobretudo, ao nível coletivo, na medida em que, ao menos teoricamente, um dispositivo de segurança deve tolerar um determinado nível de distúrbios para poder funcionar efetivamente. Ora, fica claro que, na maioria das vezes, isso não se verifica: ou seja, na menor ocorrência de um evento, a máquina se embala. Basta que um doente mental que acabou de obter o direito de sair mate alguém - o que é muito raro; basta que um estuprador que saia da prisão estupre alguém para que rapidamente a maquina se embale.

Em outra perspectiva, esses dispositivos que alegam funcionar em relação aos "riscos", à noção de "risco", à estatística e à probabilidade, demonstram tão logo um evento contrário acontece, não compreender, de fato, o que implica o "risco". Os psiquiatras são capturados nessa contradição entre, de uma parte, uma exigência defendida pelo dispositivo de segurança - de aceitação de uma margem de incerteza e de riscos necessários, que é o preço a pagar pela manutenção maximal da liberdade e da circulação dos sujeitos, e uma exigência contraditória, extremamente forte, trazida pelas mídias, pela opinião pública e pelos políticos, de redução à zero dessa margem de incerteza. Esta é a antinomia fundamental de um dispositivo de segurança. Este é o problema em que nos concentraremos para terminar a presente análise.

\section{Dispositivo de saúde mental e gestão de riscos}

Uma das características do espaço da psiquiatria no dispositivo de saúde mental é que ela é obrigada a concentrar uma parte importante de suas práticas na gestão dos "riscos". Trata-se, para ela, de avaliar os riscos ligados a uma saída, à manutenção na comunidade, etc. Vemos operar uma divisão característica entre dois tipos de situação: 1) aqueles que serão estimados como podendo evoluir na comunidade apesar de tudo - em relação a isso, primeiramente, trata-se de lhes acompanhar de maneira regular, através de um dispositivo flexível e contínuo. Para eles, a lei de 2011 institui trajetórias de cuidados, com programas de cuidados, Cad. de Pesq. Interdisc. em Ci-s. Hum-s., Florianópolis, ISSN 1984-8951 
insistindo bastante na continuidade destes, na possibilidade de modificar, em qualquer momento, o modo de acompanhamento quando há um problema.

Enfim, para esse tipo de pessoa, a fluidificação das idas e voltas entre o hospital e a comunidade. Note-se bem a importância da noção de "cuidados": é uma noção de sucesso muito importante na França atualmente. Ela permite descrever um acompanhamento maleável e indefinido, no tempo e no espaço, e dar para ele uma determinada legitimidade. 2) a outra situação se dá entre aqueles que são estimados, as que não se pode permitir evoluir na comunidade, pois eles apresentam, como dizem os termos de uma circular de aplicação da lei de 2011, "uma periculosidade potencial presumida" e para os quais algumas condições restritivas e especiais foram organizadas. Gostaríamos de sublinhar esse ponto: fluidificação e instauração de um sistema contínuo aberto/fechado, de controles e de avaliações de um lado; e, do outro, alguns processos de encerramento para pessoas consideradas muito perigosas, com, aliás, instituições fechadas que reforçam (unidades fechadas, unidades para doentes difíceis, etc.).

Quanto à psiquiatria, esta vem se inserir nos dispositivos em três níveis diferentes: 1) um papel, antes, de prevenção e de depistagem crescido, o mais perto da comunidade, no qual não insistimos, mas que é fundamental. O fato é que hoje, através do dispositivo de saúde mental, a psiquiatria se mostra no coração da cidade, em todos os níveis das relações sociais: a. Conselhos locais de saúde mental que visam tratar todas as situações de "sofrimento social", ligadas aos assistentes sociais, aos agentes municipais, aos psicólogos, etc. b. Equipes móveis psiquiatria/precariedade, que têm o intuito de tratar das situações de exclusão social, particularmente aos sem-teto. c. Psiquiatras e psicólogos do trabalho, que visam a cuidar do "sofrimento no trabalho"; 2) um papel da avaliação dos riscos em todas as etapas do dispositivo, desde as situações de crises, no domicílio ou na rua, por exemplo, até o momento das saídas depois da hospitalização; 3) um papel de controle e de acompanhamento, que perdura de maneira indefinida, a noção de "programa de cuidados sem consentimento" e a insistência na continuidade dos cuidados criando um tipo de dispositivo de obrigação flexível e indefinida.

Se nos concentramos do lado do sistema penal, constatamos exatamente o mesmo tipo de fenômeno. De um lado, como já mencionamos, existe um conjunto de iniciativas que visam, teoricamente, reduzir os encarceramentos - penas Cad. de Pesq. Interdisc. em Ci-s. Hum-s., Florianópolis, ISSN 1984-8951 v.15, n.107, p. 7-28, ago/dez 2014 
alternativas em regime aberto, deslocamento sob vigilância eletrônica, etc. A expressão "teoricamente" é utilizada no sentido de que não se trata, na realidade, de alternativas: o que se constata é que existe ao mesmo tempo um crescimento da população encarcerada e dessas penas alternativas. De uma forma mais geral, repetimos, a prisão se tornou um lugar de trajetória e um elo em uma corrente mais larga. Desse ponto de vista, a evolução mais significativa foi, desde 1998 na França, uma multiplicação das "medidas de segurança" em regime aberto que se aplica, em populações ainda mais importantes, uma vez que a pena de prisão é cumprida.

De outro lado, há uma tendência a transbordar a pena propriamente dita, efetuada em regime fechado ou aberto, configurada como um conjunto de medidas de controle e de obrigações cuja duração é indeterminada, que se executam em regime aberto. Essas medidas são fundamentadas não em relação à infração, mas em relação à "periculosidade" do sujeito e, na maioria dos casos, em função de suas necessidades de cuidados psiquiátricos. Logo, aqui também, é preciso anotar, o argumento do "cuidado psiquiátrico" permitiu criar e legitimar um sistema indefinido de controles e de obrigações indeterminadas no tempo e no espaço.

De outro lado, há a criação, para aqueles que são entendidos como não dignos de saída com essas medidas de controle indeterminadas, do que é chamado de "centros de retenção de segurança", a partir de 2008, ou seja, centros nos quais serão confinadas, depois do cumprimento da pena e por uma duração imprecisa, as pessoas que apresentem uma periculosidade muito importante. É preciso anotar, também, que o cuidado psiquiátrico foi o que legitimou a criação desses centros.

Nós achamos, aqui, as mesmas funções que vimos precedentemente. Primeiramente, um papel de avaliação dos riscos. Aqui, a transformação é bem flagrante. Durante muito tempo, a psiquiatria interveio somente para avaliar um criminoso na fase de instrução, para dizer se ele era responsável ou não por seus atos: o perito psiquiátrico operava, de alguma forma, uma divisão entre duas instituições disciplinares, a prisão ou o manicômio, em função de uma questão antes de tudo legal: ele é ou não é responsável? Pouco a pouco se ajustou, ainda no momento do processo, outra questão, de ordem disciplinar: ele é ou não é readaptável? Contudo, seu papel de avaliação sempre foi limitado à fase de instrução/processo. Hoje, as coisas são bem diferentes. É evidente que as questões de responsabilidade e de readaptabilidade permanecem, mas elas estão Cad. de Pesq. Interdisc. em Ci-s. Hum-s., Florianópolis, ISSN 1984-8951 v.15, n.107, p. 7-28, ago/dez 2014 
subordinadas ao problema fundamental da luta contra o risco da recidiva. $E$, sobretudo, a perícia do psiquiatra no tribunal é somente mais um elemento em um verdadeiro continuum de perícias e de avaliações, portando-se sobre o risco que apresenta um sujeito e sua evolução, desde a fase da instrução até a saída da prisão, momento das medidas de segurança sobre as quais discutimos aqui.

Durante todo o percurso de prisão, o sujeito é submetido às avaliações sobre o seu perfil de risco; no final do seu percurso ou da trajetória da pena, submetem-no a uma perícia de pré-liberação, que exerce um papel fundamental; depois da sua saída e do cumprimento da sua pena, caso o sujeito seja colocado em acompanhamento sócio-jurídico, ele é submetido, a cada seis meses, a pequenas perícias, praticadas pelo psiquiatra que o acompanha, para avaliar seu risco de recidiva. Brevemente, o primeiro ponto absolutamente central é que a psiquiatria se torna um elemento essencial no dispositivo contínuo de avaliação do perfil de riscos do sujeito.

Segunda função: o cuidado psiquiátrico se tornou um elemento essencial para legitimar as medidas indeterminadas de controle em regime aberto ou até mesmo de confinamento de pessoas depois do cumprimento da pena. Ele é uma das peçaschave que permitiram, na França em particular, o arrombamento da fechadura da legalidade, bem como legitimar um sistema de defesa social mirando a periculosidade de um sujeito de maneira indeterminada. Os psiquiatras podem querer se arrepender hoje, mas, em nossa opinião, são estes os primeiros responsáveis dessa evolução: não houve "instrumentalização", mas participação ativa dos psiquiatras, em nome da "vontade de cuidar", na elaboração de um dispositivo que rompe com as regras de um dispositivo legal. 


\section{Referências}

ANDREOLI, S. É a reforma psiquiátrica uma estratégia para reduzir o orçamento da saúde mental? O caso do Brasil. Rev. Bras. Psiquiatr. [online], vol.29, n.1, p.4346,2007.

DORON, C. Ce que "soin" veut dire. Quelques réflexions à propos d'une substitution de mots dans la loi du 5 juillet 2011 . Journal français de psychiatrie, vol. 1, n.38, 2013, p. 19-21.

. Evaluation de l'efficacité des psychothérapies entre sciences et société. L'Information Psychiatrique, vol. 85, n.2, février, 2009a, p. 131-141.

. L'au-delà du risque : précaution et attention. In: Psychiatries. Revue de recherche et d'échanges, n.155, sept., p. 103-118. 2011.

. La maladie mentale en question. In: Missa, J-N (dir.), Les maladies mentales. Cahiers du Centre Canguilhem, n. 2, Paris, PUF, 2008a.

. La rétention de sûreté: vers un nouveau type de positivisme juridique?

L'Information psychiatrique, n.6, 2008b, p. 533-541,

La volonté de soigner: d'un singlier désir de soin dans les politiques pénales. In: Lefève, C., Worms, F. (dir.), La philosophie du soin, Paris, PUF, 2010.

.Le principe de précaution : de l'environnement à la santé. In: Lecourt, D. (dir), La santé face au principe de précaution. Les Cahiers du Centre Canguilhem, $n^{\circ} 3$, Paris, PUF, 2009b, p. 3-40.

.Races et dégénérescence. L'émergence des savoirs sur l'homme anormal. Thèse de doctorat, Université Paris Diderot, 2011. 
Soigner par la souffrance : la prise en charge des auteurs de violences sexuelles. In: Doron, C-O, Lefève, C, Masquelet, A. (dir.), Soin et subjectivité, Les Cahiers du Centre Canguilhem, n4 Paris, PUF, 2011, p. 87-114.

.Une chaîne qui laisse toute liberté de faire le bien et qui ne permette que très difficilement de commettre le mal. In: The Carceral Notebooks, vol. 4, dir. B. Harcourt, Jul., 2008c, p. 101-130.

. Une volonté infinie de sécurité: vers une rupture générale dans les politiques pénales? In: Chevallier, P.; Greacen, T. (dir.), Folie et justice: relire Foucault, Paris, Erès, 2009c.

EWALD, F. Insurance and risk. In: Burchell, G., Gordon, C.; Miller, P. (eds.) The Foucault Effect: Studies in Governmentality. Hemel Hampstead: Harvester Wheatsheaf, 1991, p. 203.

FOUCAULT, M. La société punitive. Cours au Collège de France. 1972-1973, Paris, Hautes Etudes/EHESS-Gallimard-Seuil, 2013.

. O poder psiquiátrico. São Paulo: Martins Fontes, 2006.

Os anormais. São Paulo: Martins Fontes, 2001.

Segurança, território, população: curso dado no Collège de France (1977-1978). São Paulo: Martins Fontes, 2008.

. Vigiar e punir. Nascimento da prisão. Lisboa: Edições 70, 2013.

\begin{tabular}{l|l|}
\cline { 2 - 2 } & Artigo: \\
HARCOURT, B. Against Prediction: profiling, & Recebido em: 18/10/2014 \\
policing and punishing in an actuarial age. \\
Chicago: The University of Chicago Press, 2007.
\end{tabular}

